\title{
Hyponatremia in Diabetes Mellitus: Clues to Diagnosis and Treatment
}

\section{George Liamis, Vasilios Tsimihodimos* and Moses Elisaf}

Department of Internal Medicine, School of Medicine, University of Ioannina, Ioannina, Greece

Hyponatremia is the most common electrolyte abnormality in clinical practice and is associated with increased morbidity and mortality [1,2]. Even small decreases of serum sodium are associated with increased probability for adverse outcomes (cognitive impairment, falls, osteoporosis and fractures) [3]

Decreased serum sodium levels are occasionally observed in patients with diabetes mellitus and can be attributed to numerous underlying pathogenetic mechanisms (Table 1) $[4,5]$.

The direct measurement of serum osmolality (Posm) can differentiate between hypotonic hyponatremia (with decreased Posm) and hyponatremia associated with normal or even increased tonicity. In the latter case hyponatremia is usually due to the coexistent hyperglycemia [6]. In fact, glucose is an osmotic active substance. Thus, in cases of marked hyperglycemia Posm is increased leading to movement of water out of cells and subsequently to a reduction of serum sodium levels (dilutional hyponatremia). In such cases the corrected, for the degree of hyperglycemia, serum sodium value should be calculated. Thus, to obtain the "true" sodium level in cases of extreme hyperglycemia, the addition of $2.4 \mathrm{mEq} / \mathrm{L}$ to the measured concentration for every $100 \mathrm{mg} / \mathrm{dl}$ increment in plasma glucose above normal levels is required [7]. This corrected serum sodium level should be used during treatment of severe hyperglycemic states [8]. In patients with dilutional hyponatremia the treatment of hyperglycemia is usually followed by a normalization of serum sodium levels [4].

No hypotonic hyponatremia (with a normal measured Posm) can also be due to pseudohyponatremia associated with hyperglycemiainduced severe hypertriglyceridemia and perhaps hypovolemiainduced hyperproteinemia. It is well known that when the proportion of a serum sample occupied by substances other than water and electrolytes (such as lipids and proteins) exceeds the usual value of $7 \%$, serum sodium levels measured by ion-selective electrodes using the indirect method are falsely lower than true values [9-13]. Thus, in patients with lipemic serum and severe hypertriglyceridemia, sodium levels should be measured by direct potentiometry in blood gas panels. This method does not include a predilution step and is not susceptible to the aforementioned errors [13]. Diagnosis of pseudohyponatremia is necessary to avoid dangerous overtreatment. It should be mentioned that pseudohyponatremia does not produce any of the symptoms classically attributed to hyponatremia. Improvement in glycemic control is associated with a rapid decrease in serum triglycerides resulting in the correction of pseudohyponatremia. Thus, no specific treatment is required $[4,6]$.

The most common cause of hypotonic hyponatremia in patients with diabetes is osmotic diuresis-induced hypovolemia [4]. It should be mentioned that in patients with diabetic ketoacidosis the excretion of $\beta$-hydroxybutyrate and acetoacetate obligate urine sodium losses resulting in aggravation of hypovolemia [14]. Hypovolemia can also be due to diabetes mellitus-associated complications, such as diarrhea and vomiting.

Serum sodium levels in poorly controlled patients with diabetes mellitus vary, since these levels are the result of hyperglycemia-induced hyponatremia (dilutional hyponatremia), osmotic diuresis-induced hypotonic losses (losses of water in excess of electrolytes), which tend to increase serum sodium levels, and hypovolemia-induced decrease in serum sodium levels [4].

Drugs are a common cause of hyponatremia even in individuals with diabetes [15]. In fact, a number of drugs used in this population could result in a decrease of serum sodium levels [mainly thiazides in combination with SSRIs [16], and first generation sulphonylureas (such as tolbutamide and chlorpropamide)] [4,16]. However, a growing list of drugs implicated in the development of hyponatremia has been published [15], including NSAIDs, angiotensin converting enzyme inhibitors, rosiglitazone or even amlodipine [15]. Patients with central nervous system disorders, pulmonary disorders including lung infections, and malignancies may exhibit hyponatremia due to the syndrome of inappropriate antidiuresis [4,6,16-18]. Patients with diabetic nephropathy and chronic renal failure are very prone to the development of hyponatremia due to decreased water excretion. Additionally, diabetic patients with hyporeninemic hypoaldosteronism commonly exhibit exaggerated natriuresis leading to volume depletioninduced increase in $\mathrm{ADH}$ secretion, decreased water excretion and mild hyponatremia associated with asymptomatic hyperkalemia, and hyperchloremic metabolic acidosis [19].

Interestingly, Liamis et al have recently shown that diabetes mellitus per se is associated with hyponatremia, independently of the presence of hyperglycemia [2]. It has been suggested that the altered vasopressin regulation in diabetes mellitus, the increased insulininduced potentiation of vasopressin-induced acquaporin AQP2 water channels expression and the absorption of water from the GI tract due

\section{A) Non hypotonic hyponatremia}

With increased Posm: Hyperglycemia - induced (dilutional)

With normal Posm: Pseudohyponatremia (marked hypertriglyceridemia and hyperproteinemia)

\section{B) Hypotonic hyponatremia}

- Hypovolemia-induced

- Drug -induced hyponatremia (mainly with thiazides and first generation sulphonylureas)

- Diabetes mellitus - associated hyponatremia

- Syndrome of inappropriate antidiuresis associated with coexisting disorders or administered drugs

- Chronic renal failure (diabetic nephropathy) or associated with the syndrome of hyporeninemic hypoaldosteronism

Table 1: Causes of hyponatremia in diabetic patients.

*Corresponding author: Vasilis Tsimihodimos, Department of Internal Medicine, Medical School, University of Ioannina, 45110 loannina, Greece, Tel: +302651007623; Fax: +302651007016; E-mail: tsimiho@gmail.com

Received April 27, 2015; Accepted May 27, 2015; Published May 30, 2015

Citation: Liamis G, Tsimihodimos V, Elisaf M (2015) Hyponatremia in Diabetes Mellitus: Clues to Diagnosis and Treatment. J Diabetes Metab 6: 560 doi:10.4172/2155-6156.1000560

Copyright: $\odot 2015$ Liamis G, et al. This is an open-access article distributed under the terms of the Creative Commons Attribution License, which permits unrestricted use, distribution, and reproduction in any medium, provided the original author and source are credited. 
Citation: Liamis G, Tsimihodimos V, Elisaf M (2015) Hyponatremia in Diabetes Mellitus: Clues to Diagnosis and Treatment. J Diabetes Metab 6: 560. doi:10.4172/2155-6156.1000560

Page 2 of 3

to slower stomach emptying may play a role in the association between diabetes mellitus and decreased serum sodium levels [20,21].

Taking in to consideration the multifactorial origin of hyponatremia in most patients with diabetes a cause-specific treatment is required. Discontinuation of culprit medications and avoidance of readministration is advised. Administration of insulin drives glucose and water into the cells, reverses the initial direction of water movement and results in an increment of serum sodium levels. Treatment of underlying factors (e.g hypovolemia, infections) that can contribute to or provoke hyponatramia is also of paramount importance.

The careful and proper management of hypovolemia (with saline solutions and also potassium chloride solutions, if hypokalemia is present) can also increase serum sodium levels. It should be acknowledged that potassium ions should also be taken into account in the calculation of the tonicity of the administered fluids to avoid inappropriate overcorrection of hyponatremia as well as circulatory overloading $[22,23]$. Thus, potassium chloride should be added in hypotonic fluids, whereas the administration of normal saline plus potassium chloride should be avoided in most circumstances [24].

Hypertonic saline should be given only for severely symptomatic hyponatremia (e.g., seizures) to rapidly increase serum sodium concentration until the symptoms subside whereas less symptomatic hyponatremia may be corrected at a slower pace. In all cases, however, the increase in serum sodium concentration should be limited to 10 $\mathrm{mmol} / \mathrm{l}$ in the first $24 \mathrm{~h}$ and $8 \mathrm{mmol} / \mathrm{l}$ during every $24 \mathrm{~h}$ thereafter. The therapeutic target should be even lower (i.e. $<4-6 \mathrm{mmol} / \mathrm{L}$ ) in the presence of risk factors for the development of the osmotic demyelination syndrome [25]. It should be emphasized that patients with diabetes are at high risk for the development of the osmotic demyelination syndrome during rapid correction of hyponatremia. In fact, they commonly exhibit risk factors that predispose to this disorder, such as malnutrition, hypokalemia, and hypoxia [26]. In Figure 1 a detailed algorithm for the differential diagnosis of hyponatremia in diabetic patients is illustrated.

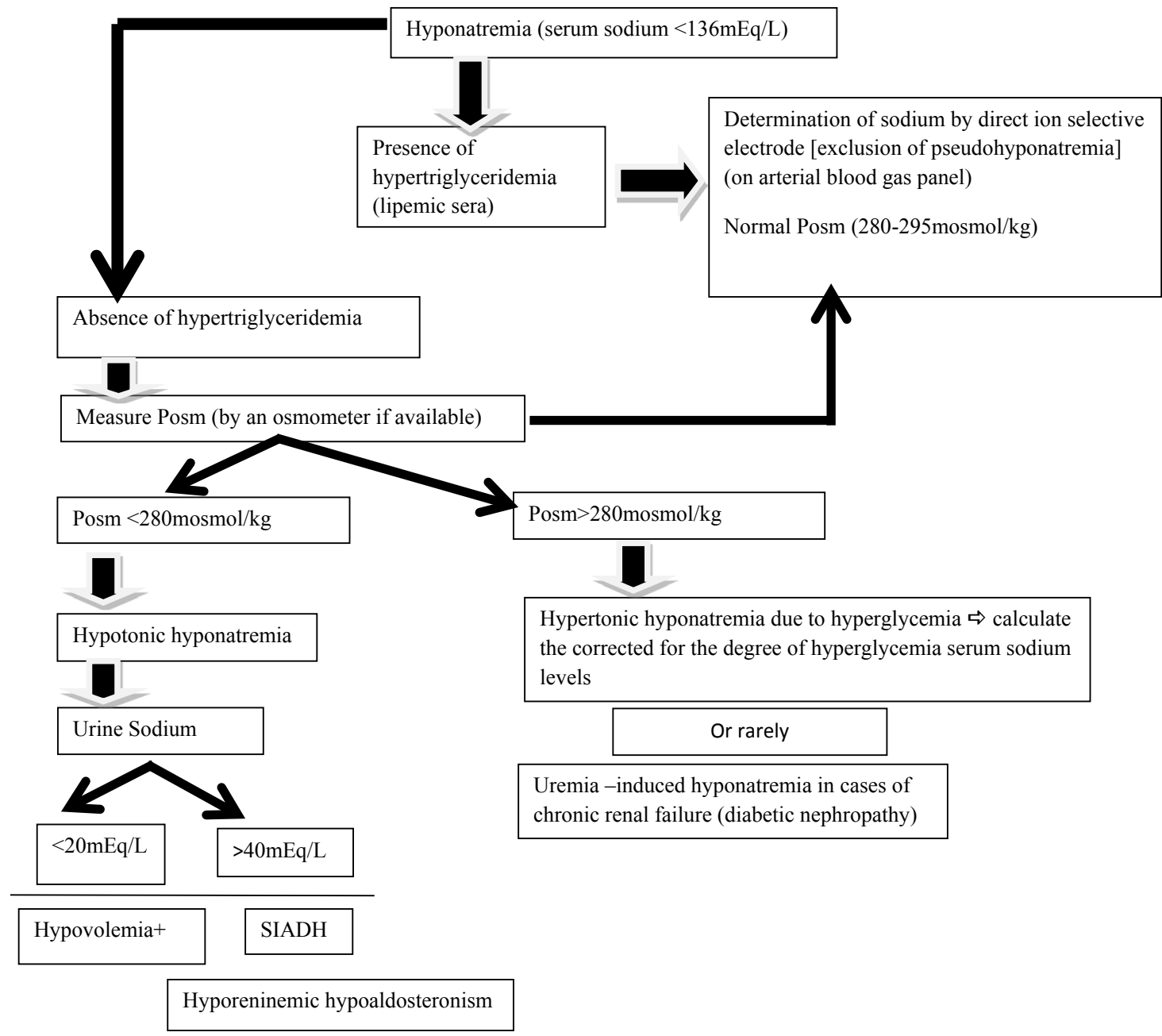

+ It should be mentioned that in hypovolemic patients on diuretics or with increased osmotic diuresis urine sodium may be higher than $20 \mathrm{msEq} / \mathrm{L}$

Figure 1: Diagnostic algorithm in diabetic individuals with hyponatremia 
Citation: Liamis G, Tsimihodimos V, Elisaf M (2015) Hyponatremia in Diabetes Mellitus: Clues to Diagnosis and Treatment. J Diabetes Metab 6: 560. doi:10.4172/2155-6156.1000560

Page 3 of 3

\section{References}

1. Waikar SS, Mount DM, Curhan GC (2009) Mortality after hospitalization with mild, moderate, and severe hyponatremia. Am J Med 122: 857-865.

2. Liamis G, Rodenburg EM, Hofman A, Zietse R, Stricker BH, et al. (2013) Electrolyte disorders in community subjects: prevalence and risk factors. Am J Med 126: 256-263.

3. Podesta MA, Faravelli I, Cucchiari D, Reggiani F, Oldani S, et al. (2015) Neurological counterparts of hyponatremia: pathological mechanisms and clinical manifestations. Curr Neurol Neurosci Rep 15: 18.

4. Liamis G, Liberopoulos E, Barkas F, Elisaf M (2014) Diabetes mellitus and electrolyte disorders. World J Clin Cases 2: 488-496.

5. Elisaf MS, Tsatsoulis AA, Katopodis KP, Siamopoulos KC (1996) Acid-base and electrolyte disturbances in patients with diabetic ketoacidosis. Diabetes Res Clin Pract 34: 23-27.

6. Milionis HJ, Liamis GL, Elisaf MS (2012) The hyponatremic patient: a systematic approach to laboratory diagnosis. CMAJ 166: 1056-1062.

7. Hillier TA, Abbott RD, Barrett EJ (1999) Hyponatremia: evaluating the correction factor for hyperglycemia. Am J Med 106: 399-403.

8. Liamis G, Gianoutsos C, Elisaf MS (2009) Hyperosmolar nonketotic syndrome with hypernatremia: how can we monitor treatment? Diabetes Metab 26: 403405 .

9. Goldwasser P, Ayoub I, Barth RH (2015) Pseudohypernatremia and pseudohyponatremia: a linear correction. Nephrol Dial Transplant 30: 252-257.

10. Liamis G, Liberopoulos E, Barkas F, Elisaf M (2013) Spurius electrolyte disorders: a diagnostic challenge for clinicians. Am J Nephrol 38: 50-57.

11. Weisberg LS (1989) Pseudohyponatremia: a reappraisal. Am J Med 86: 315318

12. Turchin A, Seifter JL, Seely EW (2003) Clinical problem-solving. Mind the gap. N Engl J Med 349: 1465-1469.

13. Lai MY, Lin CC, Chung SL, Wu CH, Yang WC, et al. (2009) Milky plasma, diabetes, and severe hyponatremia. Kidney Int 75: 996.
14. Chiasson JL, Aris-Jilwan N, Belanger R (2003) Diagnosis and treatment of diabetic ketoacidosis and the hyperglycemic hyperosmolar state. CMAJ 168: 859-866.

15. Liamis G, Milionis $\mathrm{H}$, Elisaf M (2008) A review of drug-induced hyponatremia. Am J Kidney Dis 52: 144-153.

16. Blijderveen JC, Straus SM, Rodenburg EM, Zietse R, Stricker BH, et al. (2014) Risk of hyponatremia with diuretics: chlorthalidone versus hydrochlorothiazide. Am J Med 127: 763-771.

17. Liamis G, Milionis HJ, Elisaf M (2011) Hyponatremia in patients with infectious diseases. J Infect 63: 327-335.

18. Liamis G, Milionis HJ, Elisaf M (2011) Endocrine disorders; causes of hyponatremia not to neglect. Ann Med 43: 179-187.

19. DeFronzo RA (1980) Hyperkalemia and hyporeninemic hypoaldosteronism Kidney Int 17: 118-134.

20. Bankir L, Bardoux nP, Ahloulay M (2001) Vasopressin and diabetes mellitus. Nephron 87: 8-18.

21. Bustamante M, Hasler U, Kotova O, Chibalin AV, Mordasini D, et al. (2005) Insulin potentiates AVP-induced AQP2 expression in cultured renal collecting duct principal cells. Am J Physiol Renal Physiol 288: F334-F344.

22. Adrogue HJ, Madias NE (2012) The challenge of hyponatremia. J Am Soc Nephrol 23: 1140-1148.

23. Adrogue HJ, Madias NE (2014) Diagnosis and treatment of hyponatremia. Am J Kidney Dis 64: 681-684.

24. Liamis G, Filippatos TD, Elisaf MS (2015) Correction of hypovolemia with crystalloid fluids: Individualizing infusion therapy. Postgrad Med 127: 405-412.

25. Verbalis JG, Goldsmith SR, Greenberg A, Korzelius C, Schrier RW (2013) Diagnosis, evaluation, and treatment of hyponatremia: expert panel recommendations. Am J Med 126: S1-42.

26. Kallakatta RN, Radhakrishnan A, Fayaz RK, Unnikrishnan JP, Kesavadas C et al. (2011) Clinical and functional outcome and factors predicting prognosis in osmotic demyelination syndrome (central pontine and / or extrapontine myelinolysis) in 25 patients. J Neurol Neurosurg Psychiatry 82: 326-331. 